\title{
FOREWORD
}

\section{Special Section on Medical Imaging}

\begin{abstract}
Medical imaging has contributed significantly to progresses in basic medicine, clinical medicine, and medical education. Also, imaging modalities and computer system with high processing ability have been improved dramatically over the last decade. As these technology advances, the development of innovative algorithms and applications is demanded in the medical imaging field. This field consists of research and development covering a number of disciplines, including medicine, biology, engineering, and information science. Furthermore, it is desirable to build a new academic framework as a synthesis of these research fields. Because of such reasons, a special section, as the first time in English edition in IEICE Information and Systems D journal, was planned to further promote research and development of future medical imaging technology. We also have a simultaneous special section on medical imaging in Japanese edition of IEICE D journal.
\end{abstract}

We received a total of 30 submissions: 2 for survey, 24 for paper, and 4 for letter. Each manuscript was carefully reviewed, and 2 surveys, 7 papers and 2 letters were accepted for publication. We had to reject some of the interesting papers, since it is the editorial policy of IEICE transactions to reject a manuscript that requires a major revision. We hope we could see the revised versions of these manuscripts in the future issues of the IEICE transactions. In addition, we have 2 invited papers, 11 papers, and 3 letters in simultaneously published Japanese edition.

The Editorial Committee would like to thank all the authors who submitted their high-quality papers and also all the reviewers for their considerable efforts to maintain the quality of the selected papers high under a tight schedule. Finally, as the Guest Editor-in-Chief, I would like to express my sincere gratitude to all the Editorial Committee Members for their outstanding volunteer efforts during the entire process of publishing this Special Section.

Special Section Editorial Committee

Guest Editor-in-Chief: Hiroshi FUJITA (Gifu University)

Guest Editor-in-Vice Chief: Yoshito MEKADA (Chukyo University)

Guest Editors: Mikio SUGA (Chiba University), Ryo HARAGUCHI (National Cerebral and Cardiovascular Center Research Institute), Ken'ichi MOROOKA (Kyushu University)

Guest Associate Editors: Hidetaka ARIMURA (Kyushu University), Takashi OBI (Tokyo Institute of Technology), Akiko KANO (Konica Minolta Medical \& Graphic, Inc), Yoshiki KAWATA (The University of Tokushima), Takayuki KITASAKA (Aichi Institute of Technology), Yuichi KIMURA (National Institute of Radiological Sciences), Tetsuo SATO (Nara Institute of Science and Technology), Akinobu SHIMIZU (Tokyo University of Agriculture and Technology), Hayaru SHOUNO (The University of Electro-Communications), Kazuhiko HAMAMOTO (Tokai University), Takeshi HARA (Gifu University), Hidekata HONTANI (Nagoya Institute of Technology), Yoshitaka MASUTANI (The University of Tokyo), Masahiro YAMAGUCHI (Tokyo Institute of Technology)

Advisory Members: Jong Hyo KIM (Seoul National University; Korea), Jong Beom RA (KAIST; Korea), Ruey-Feng CHANG (National Taiwan University; Taiwan), Pai-Chi LI (National Taiwan University; Taiwan), Tianzi JIANG (The Chinese Academy of Sciences; China), David ZHANG (The Hong Kong Polytechnic University; China), Wieslaw NOWINSKI (Agency for Science, Technology \& Research; Singapore), Yoshinobu SATO (Osaka University; Japan)

Hiroshi Fujita (Gifu University), Guest Editor-in-Chief

\begin{abstract}
Hiroshi Fujita (Fellow) received the B.S. and M.S. degrees in Electrical Engineering from Gifu University, Japan, in 1976 and 1978, respectively, and Ph.D. degree from Nagoya University in 1983. He became a research associate in 1978 and an associate professor in 1986 at Gifu National College of Technology. He was a visiting researcher at the K. Rossmann Radiologic Image Laboratory, University of Chicago, in 1983-1986. He became an associate professor in 1991 and a professor in 1995 in the Faculty of Engineering, Gifu University. He has been a professor and chair of intelligent image information since 2002 at the Graduate School of Medicine, Gifu University. He served as a chair of the Research Group on Medical Imaging in IEICE in 2007 and 2008. He is currently a President of the Society for Medical Image Information in Japan.
\end{abstract}

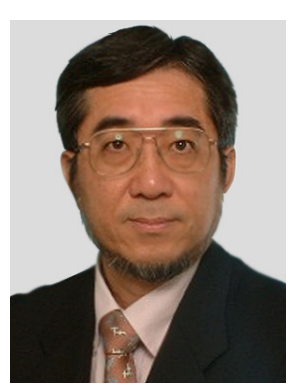

